\title{
ANALISIS STRUKTUR DAN FUNGSI TEKS IKLAN LAYANAN MASYARAKAT
}

\author{
STRUCTURE AND FUNCTION ANALYSIS OF COMMUNITY SERVICE ADVERTISING \\ TEXT
}

Restu Sukesti

Balai Bahasa Provinsi Daerah Istimewa Yogyakarta

Jalan I DewaNyoman Oka 34 Yogyakarta, Indonesia

sukestirestu@gmail.com
(Naskah diterima tangga 15 September 2021, direvisi terakhir tanggal 10 November 2021, dan disetujui tanggal 13 November 2021)

DOI: https:// doi.org/10.26499/wdprw.v49i2.893

\begin{abstract}
Public service advertisements (PSA) as a means of communication "govern" to the public even though the form of commanding is in the form of orders, prohibitions, appeals, and suggestions. PSAs in internet media use pictures and writing, both together as a means of communication, but what can "talk" a lot is language. Language in PSAs, hereinafter referred to as text, is studied in this study with a qualitative descriptive approach and with research methods: data collection (download and copy techniques), data analysis (text structure analysis (discourse) techniques), language structure analysis techniques/grammar, and analytical techniques pragmatics). The results obtained indicate that there are three forms of ILM text, namely only images, a mixture of images and writings, and only text; 2) PSA text composition consists of themes, supports, and illustrations; 3) the language in ILM uses a mixture of foreign vocabulary, and verbs with-kan, -i, and klitika-lah. the peculiarity of the message in the PSA text is in the form of a commanding message, either directly or indirectly.
\end{abstract}

Keywords: public service advertisement text; text structure; text composition; text specificity

\begin{abstract}
Abstrak
Iklan layanan masyarakat (ILM) sebagai sarana komunikasi memberikan "perintah" pada masyarakat dan wujud perintah itu berupa suruhan, larangan, imbauan, dan saran. ILM dalam media internet menggunakan sarana gambar dan tulisan, keduanya bersama sebagai sarana komunikasi, tetapi yang dapat "berbicara" banyak ialah sarana bahasa. Bahasa dalam ILM, selanjutnya disebut teks dikaji dalam penelitian ini dengan pendekatan deskriptif kualitatif dan dengan metode penelitian: penjaringan data (teknik unduh dan salin), penganalisisan data (teknik analisis struktur teks (wacana), teknik analisis sturktur bahasa/gramatika, dan teknik analisis pragmatik). Hasil yang diperoleh menunjukkan bahwa 1) bentuk teks ILM ada tiga, yaitu hanya gambar, campuran gambar dan tulisan, dan hanya tulisan; 2) komposisi teks ILM terdiri atas tema, pendukung, dan ilustrasi; 3) bahasa pada ILM memanfaatkan campuran kosakata asing, dan verba berafiks -kan, -i, dan klitika -lah, 4) kekhasan kosakata pada teks ILM ialah menggunakan kata "imperatif" (jangan, ayo, mari, dsb.); dan 5) kekhasan pesan pada teks ILM ialah berupa pesan memerintah, baik secara langsung maupun taklangsung.
\end{abstract}

Kata-kata kunci: teks iklan layanan masyarakat; struktur teks; komposisi teks; kekhasan teks 


\section{Pendahuluan}

Iklan pada umumnya merupakan tawaran akan suatu produk atau jasa kepada khalayak (masyarakat), yang mengharapkan masyarakat menjadi konsumen produk atau jasanya. Iklan seperti itu disebut iklan komersial karena pemilik iklan mengharapkan imbalan uang dari yang ia jual. Namun, ada iklan yang tidak komersial, yaitu iklan layanan masyarakat. Meskipun tidak komersial, aspek persuasif iklan layanan masyarakat juga perlu diperhatikan karena iklan layanan masyarakat tetap bertujuan untuk "memerintah". Dalam iklan audiovisual, bahasa berkolaborasi dengan aspek visual dan audio; dalam iklan visual (seperti dalam kajian ini), bahasa berkolaboarsi dengan aspek visual (gambar, tipografi, warna, dsb.) Iklan terdiri atas unsur verbal dan non-verbal, bahasa termasuk ke dalam unsur verbal (Program, dkk., 2015: 160).

Iklan layanan masyarakat ialah suatu imbauan kepada masyarakat untuk melakukan sesuatu yang bermanfaat bagi dirinya ataupun bagi orang lain. Iklan ini tidak bersifat komersial karena tidak ada tawaran produk atau jasa yang harus dibeli. Iklan itu hanya cenderung mengajak masyarakat untuk melakukan sesuatu agar lebih baik dalam hal kesehatan, kebersihan, keindahan, kemajuan, dsb. Iklan layanan masyarakat tetap bagian dari pesan persuasif untuk kepentingan masyarakat, baik masyarakat individu maupun masyarakat luas yang terlepas dari unsur komersial (Program, dkk. 2015). Selain itu, iklan layanan masyarakat juga didesain komunikatif dan atraktif agar pesan dapat disampaikan dengan baik. Hal itu merupakan strategi iklan layanan masyarakat (Setiawan, 2015: 19).

Iklan layanan masyarakat dapat dipasang di papan baliho, spanduk, pamflet, poster, atau yang lain di ruang publik; dapat ditayangkan di media elektronik (televisi); dapat disiarkan di media radio; dapat dimuat di media cetak (majalah, koran), dan di media internet. Pada penelitian ini, iklan yang dibahas ialah iklan layanan masyarakat yang terdapat pada media internet, yaitu dari ruang laman (website) dan blog.

Iklan di media internet relatif banyak ditemukan karena zaman sekarang orang lebih banyak melihat (membaca) informasi melalui media tersebut. Untuk itu, pemasang iklan layanan masyarakat akan merasa lebih berhasil jika dimuat di internet. Iklan layanan masyarakat dapat berupa gambar, video, dan atau teks (tulisan). Sementara itu, dalam suatu kajian kebahasaan, akan lebih tepat jika kajian atas iklan ialah yang berupa teks, meskipun unsur lain tidak diabaikan karena seluruh aspek dalam iklan adalah satu kesatuan tawaran atau pesan. Untuk itu, bahasa sangat penting dalam sebuah iklan. Bahasa sebagai alat komunikasi yang sangat penting dan mampu sebagai yang memainkan aspek dan efek komunikasi (Sukamto and Kartikawangi, 2012: 1). Selain itu, Bahasa dalam iklan memuat kesan bahwa bahasa iklan itu merupakan landskap bahasa persuasif, seperti halnya bahasa pada papan nama merupakan landskap sosiobudaya (Erikha, 2018: 50).

Banyak hasil penelitian yang mebahas iklan, baik iklan komersial maupun iklan layanan masyarakat (non-komersial). Sukamto and Kartikawangi (2012) mengkaji bahasa dalam iklan Citra yang mencitrakan perempuan Indonesia bukan sebagai warga subordinat dalam masyarakat. Dalam kajian itu dinyatakan bahwa bahasa bagian dari daya tarik iklan sejalan dengan efek visualisasi dan narasi. Pada efek narasi 
itulah bahasa berperan penting untuk membangun kesan dan pesan iklan.

Kajian kebahasaan terkait iklan sudah banyak dilakukan, antara lainkajian iklan dari aspek kebahasaan, yaitu (Wati, 2015) menyebutkan bahwa dalam iklan (papan nama) menggunakan bahasa Indonesia yang tercampuri kosakata dan istilah bahasa asing, adanya kesalahan ejaan dan gramatika; (Purnami, 2017), hasil kajiannya ialah iklan memanfaatkan berbagai bentuk kebahasaan (akronim, singkatan, dan nama diri); Rahmanadia (2012) menghasilkan temuan bahwa iklan memiliki skemata yang merupakan kerangka imajinasi atas iklan tersebut.

Prinsip iklan sebenarnya mempromosikan produknya, baik sebagai iklan komersial maupun iklan layanan masyarakat (nonkomersial). Untuk mencapai tujuan itu, penyampaian pesan tersebut secara tersurat dan tersirat. Kajian yang tersirat dalam iklan masuk ranah pragmatik, hingga saat ini telah banyak dilakukan, antara lain (Sumarsih, 2018) mengatakan bahwa iklan memiliki strategi dan fungsi tindak tutur direktif; (Shofa dan Astri Utami, 2017) mengamati bahwa iklan memiliki makna dan tanda dari sudut semiotika; (Setiyanto, 2013) membahas iklan rokok yang mengandung metapesan.

Pada prinsipnya iklan sebagai upaya membangun citra dan imajinasi positif atas yang diiklankan di tengah masyarakat (Suryo Nugroho, 2012). Selain itu, Suwitra dan Suarjana (2018) mengkaji iklan kesehatan dalam persprektif semiotik. Hasilnya ialah bahasa yang digunakan dalam iklan layanan masyarakat merupakan bahasa yang tidak resmi, tetapi singkat dan padat. Didalamnya terdapat sesuatu yang ditandai (petanda/ signified) dan yang menandai (penanda/ signfier) dalam bingkai semiotika.

Permasalahan yang muncul dalam teks iklan layanan masyarakat di internet yang hadir secara visual dan tekstual ialah (1) bagaimana bentuk teks iklan layanan masya- rakat; (2) bagaimana komposisi struktur teks iklan layanan masyarakat; (3) bagaimana pemanfaatkan bahasa dalam teks iklan layanan masyarakat; (4) bagaimana kekhasan kosakata dalam teks iklan layanan masya-rakat; dan (5) bagaimana pesan imperatif pada iklan layanan masyarakat.

Dengan itu, kajian ini bertujuan memecahkan masalah yang ada, yaitu (1) mendeskripsikan bentuk teks iklan layanan masyarakat; (2) mendeskripsikan komposisi struktur teks iklan layanan masyarakat; (3) mendeskripsikan pemanfaatkan bahasa dalam teks iklan layanan masyarakat; (4) mendeskripsikan kekhasan kosakata dalam teks iklan layanan masyarakat; dan (5) kekhasan pesan imperatif pada iklan layanan masyarakat.

Untuk itu, dalam penelitian ini digunakan teknik penganalisisan data (teknik analisis struktur teks/wacana untuk membahas permasalahan 1 dan 2; teknik analisis struktur bahasa/gramatika untuk membahas permasalahan 3 dan 4, dan teknik analisis pragmatik tindak tutur untuk membahas permasalahan 5 .

\section{Metode}

Ada tiga tahap dalam penelitian ini, yaitu tahap pemerolehan data, penganalisisan data, dan penyajian hasil analisis (Pribady, 2018: 14-15). Pada tahap pemerolehan data digunakan teknik unduh teks iklan dalam media internet. Teks iklan yang telah diunduh diklasifikasi menjadi beberapa kelompok. Pengelompokan itu berdasarkan jenis teks iklan, komposisi teks iklan, dan pemanfaatan bahasa dalam iklan layanan masyarakat.

Data dalam penelitian ini ialah bahasa pada iklan layanan masyarakat (ILM) yang terdapat pada media internet yang dalam bentuk gambar bukan animasi atau bukan dalam efek gerak dan lagu. Iklan itu pun bersifat umum, tidak mengarah pada jenis 
spesifikasi iklan tertentu, bersifat umum sebagai sebuah iklan layanan masyarakat bukan sebagai iklan komersial.

Dalam penganalisis digunakan metode deskriptif kualitatif. Deskriptif artinya hasil pembahasan diwujudkan dalam bentuk kata kata yang membangun teks hasil kajian secara ilmiah; kualitatif artinya dalam pembahasan itu tidak mengindahkan jumlah data yang terwakili. Oleh karenanya, jika ditemukan hanya satu data pada kelompok klasifikasi, hal itu tidak akan membedakan penganalisisannya dengan banyak data pada kelompok klasifikasi lain.

\section{Hasil dan Pembahasan}

\subsection{Bentuk Iklan Layanan Masyarakat}

Ada tiga buah iklan layanan masyarakat dalam bentuk poster, yaitu yang berbentuk bahasa tulis dan gambar, berbentuk hanya bahasa tulis, dan berbentuk komik.

\subsubsection{Iklan Layanan Masyarakat yang Berbentuk Bahasa Tulis dan Gambar} Iklan layanan masyarakat itu dibatasi pada iklan poster. Karena berbentuk poster, iklan itu disajikan dalam bahasa yang berdampingan dengan gambar, warna, dan tipografi.

Iklan 1

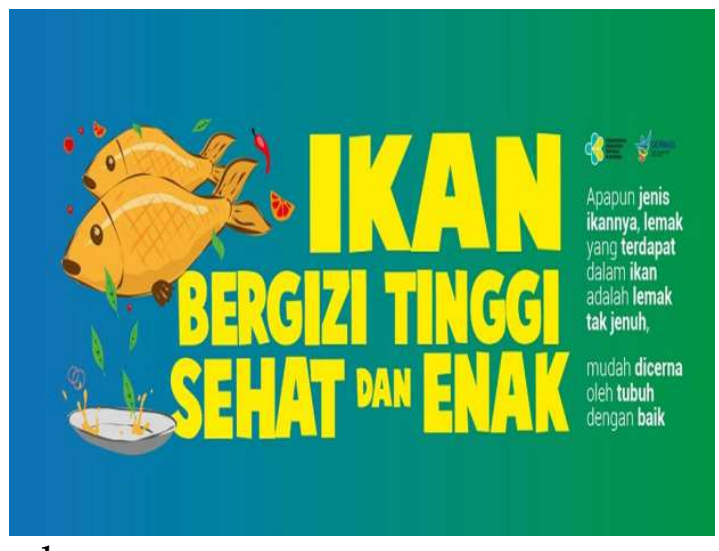

(sumber:

https:/ / promkes.kemkes.go.id/poster-ikanbergizi-tinggi70x100 $\mathrm{cm}$ )

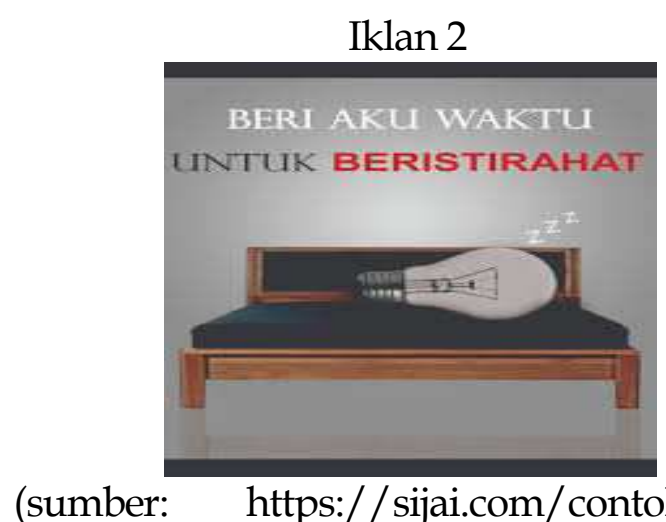

layanan-masyarakat/)

Kedua iklan tersebut memanfaatkan bahasa tulis dan gambar. Keduanya saling mendukung untuk menguatkan pesan yang disampaikan. Pada iklan 1 tersampaikan pentingnya makan ikan dengan ilustrasi gambar ikan, dan iklan 2 tersampaikan pesan secara berkala padamkan listrik (di rumah) agar listrik "beristirahat" dengan ilustrasi bola lampu yang sedang tidur. Hanya bedanya, iklan 1 , pesan tersampaikan dapat dengan bahasa tulis saja sehingga gambar hanya untuk memperkuat pesan. Namun, iklan 2 pesan belum tersampaikan dengan hanya bahasa tulis karena pesan pada bahasa tulis belum eksplisit atau belum tuntas sehingga ilustrasi gambar bola lampu tidur menjadi wajib. Dengan demikian, iklan dengan kombinasi bahasa tulis dan gambar ada dua, yaitu pesan tersampaikan secara eksplisit dan tuntas dalam bahasa tulis sehingga gambar hanya sebagai penguat; dan pesan tersampaikan secara eksplisit dan tuntas harus oleh bahasa tulis dan gambar.

3.1.2 Iklan Layanan Masyarakat yang Berbentuk Bahasa Tulis Tanpa Gambar Bentuk kedua ialah iklan layanan masyarakat dalam bentuk poster yang berbentuk bahasa tulis, seperti berikut. 


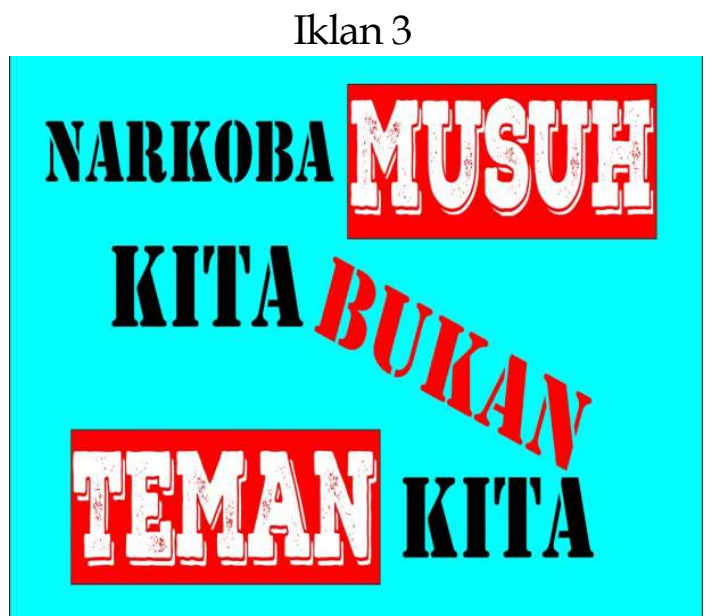

(sumber: https://richagambar.blogspot.com) Iklan tersebut berwujud bahasa tulis yang disertai tipografi dan warna tulisan. Penekanan pesan ditopang dengan warna tulisan, yaitu dengan warna merah atau warna yang mencolok.

\subsubsection{Iklan layanan Masyarakat yang} Berbentuk Komik

Iklan layanan masyarakat yang ketiga berbentuk komik. Penyajiannya seperti komik, yaitu cerita dengan ilustrasi bahasa tulis dan gambar. Cerita itu berisipesan yang disampaikan kepada masyarakat.

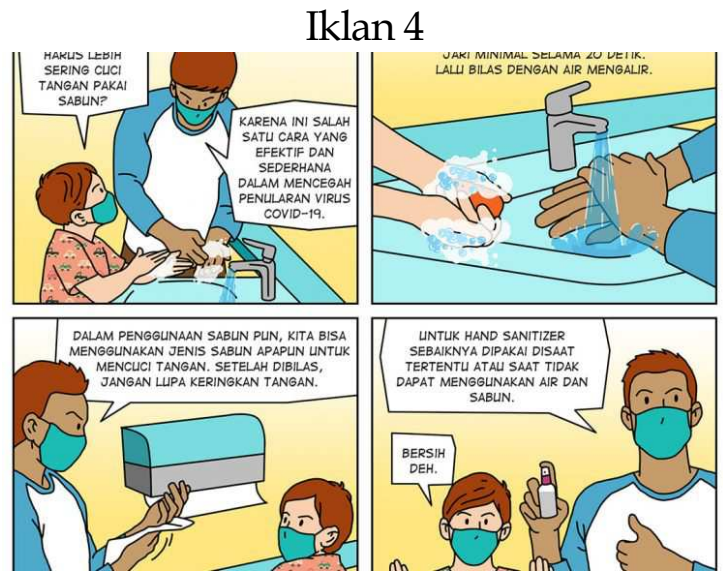

(sumber: https://sehatnegeriku.kemkes.go.id)

Iklan 4 berbentuk komik. Iklan 4 mengandung pesan bahwa sebelum makan makanan, orang harus mencuci tangan lebih dulu.

\subsection{Struktur Teks Iklan Layanan Masyarakat}

Teks iklan merupakan sebuah wacana. Jika itu iklan komersial, inti wacana ialah perintah (secara halus) atau ajakan untuk membeli barang atau jasa yang diiklankan sehingga komposisi wacananya terdiri atasnama pro-duk, penjelasan produk, dan keunggulan produk. Namun, jika itu iklan layanan ma-syarakat (nonkomersial), inti wacana ialah ajakan, imbauan, atau perintah sehingga komposisi wacananya terdiri atas tema/judul iklan, penjelasan iklan, ajakan/saran/perintah untuk dilaksanakan, pembuat iklan, dan pelengkap iklan.

\subsubsection{Komposisi Sajian Teks}

Komposisi wacana iklan layanan masyarakat ialah tema/judul iklan, penjelasan iklan, dan ajakan/saran/perintah untuk dilaksanakan.

\section{(1) Tema/Judul Produk}

Yang dimaksud dengan tema/judul ialah hal yang diiklankan atau tentang hal apa yang akan disampaikan. Hampir setiap iklan layanan masyarakat memuat tema/judul ini, seperti pada contoh berikut.

(1) "Mematikan Lampu dan Peralatan Elektronik di rumah Anda"

Ungkapan tersebut merupakan tema pada iklan layanan masyarakat (iklan 5) berikut. 


\section{Iklan 5}

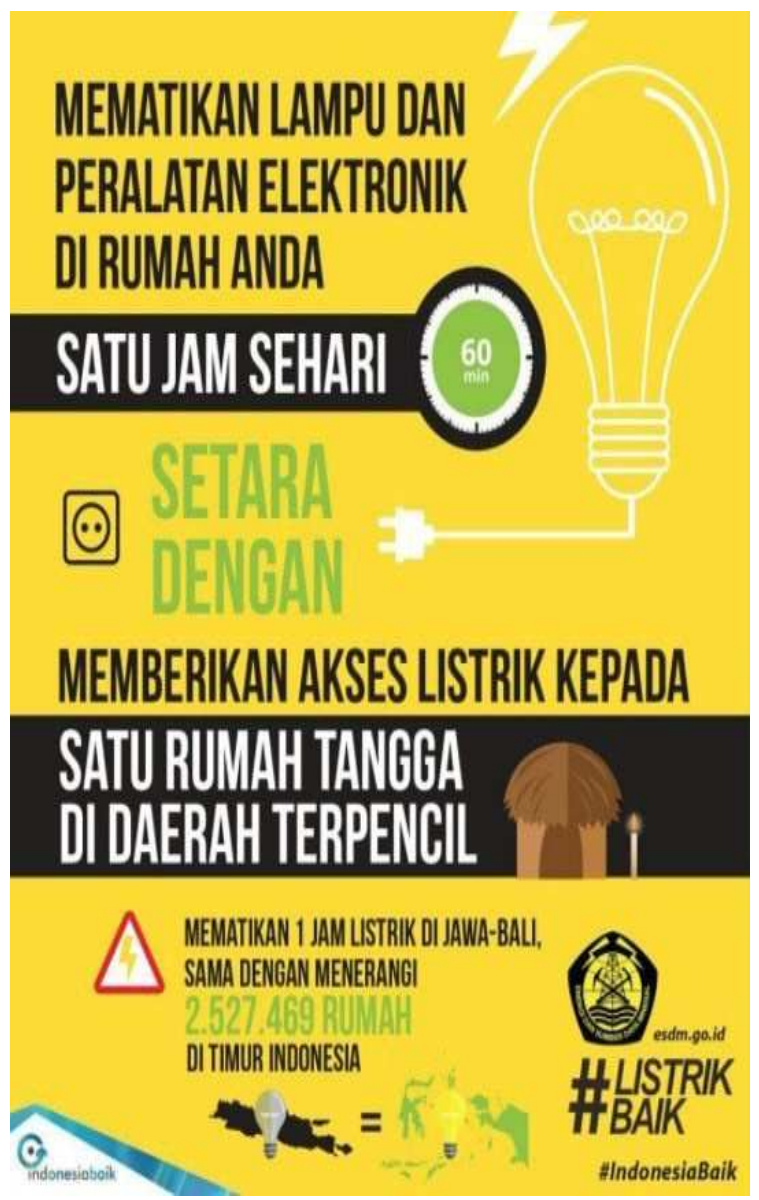

(sumber: https://www.askara.co)

\section{(2) Penjelasan Iklan}

Penjelasan produk pada iklan 5 ialah sebagai berikut.

(2) "Setara dengan Memberikan Akses Listrik kepada satu Rumah Tangga di daerah Terpencil"

(3) "Mematikan 1 Jam Listrik di Jawa-Bali, sana dengan Menerangi 2.527.469 Rumah di Timur Indonesia"

Kedua ungkapan tersebut merupakan uraian atau penjelasan dari tema iklan. Kalimatnya cenderung dekriptif yang bertujuan menjelaskan maksud tema iklan.

\section{(3) Ajakan, Saran, Perintah Iklan}

Ajakan/saran/perintah dalam iklan layanan masyarakat dapat berupa tuturan langsug atau tidak langsung. Jika perintah itu berupa tuturan langsung, bahasa yang digunakan terdapat kata-kata yang bermakna 'ajakan, larangan, perintah, imbauan' atau disebut kalimat imperatif. Namun, jika perintah itu bukan tuturan langsung, bahasa yang digunakan tidak menggunakan kata-kata ajakan, larangan, perintah, imbauan, dan sebagainya, tetapi hanya kalimat deklaratif bukan imperatif. Ajakan pada iklan 5 merupakan tuturan tidak langsung, seperti berikut.

(4) 'Dengan mematikan listrik satu jam di rumah, akan membawa manfaat luar biasa bagi kehidupan orang lain'.

Ungkapan ajakan tersebut berbentuk kalimat deklaratif bukan imperatif, tetapi bermaksud perintah/ajakan untuk mematikan listrik agar listrik hemat dan dapat membantu kehidupan orang lain. Tuturan perintah/ajakan tersebut sebagai tuturan tidak langsung.

\section{(4) Pembuat Produk}

Sebuah iklan layanan masyarakat pada umumnya disertai institusi/lembaga yang mengiklankan karena bersifat non-profit. Dalam iklan 5 tertulis ESDM (Kementerian Energi Sumber Daya Mineral) sebagai pembuat atau pemilik iklan.

\section{(5) Pelengkap Iklan}

Tujuan pembuatan iklan layanan masyarakat yang berupa poster ialah menarik pembaca untuk membaca, memahami, dan melaksanan perintahnya. Agar semua tujuan itu tercapat poster dibuat semenarik mungkin, salah satunya dengan permainan warna, tipografi tulisan, dan gambar sebagai ilustrasi, yang semua itu disebut sebagai pelengkap iklan. Dalam iklan 5, pelengkap iklan ialah pemilihan warna cerah (kuning) dan gambar bola lampu dan ada tagar Indonesia Baik.

\subsubsection{Variasi Komposisi}

Iklan layanan masyarakat dalam bentuk poster memiliki beberapa aspek, yaitu 1) 
tema/judul, 2) penjelasan tema, 3) ajakan/ perintah, 4) pembuat produk, dan 6) peleng kap iklan. Ada iklan layanan masyarakat yang memiliki aspek tersebut secara leng kap, dan ada yang tidak lengkap.

(1) Iklan Layanan Masyarakat Berunsur Lengkap

Iklan yang lengkap ialah sebagai berikut.

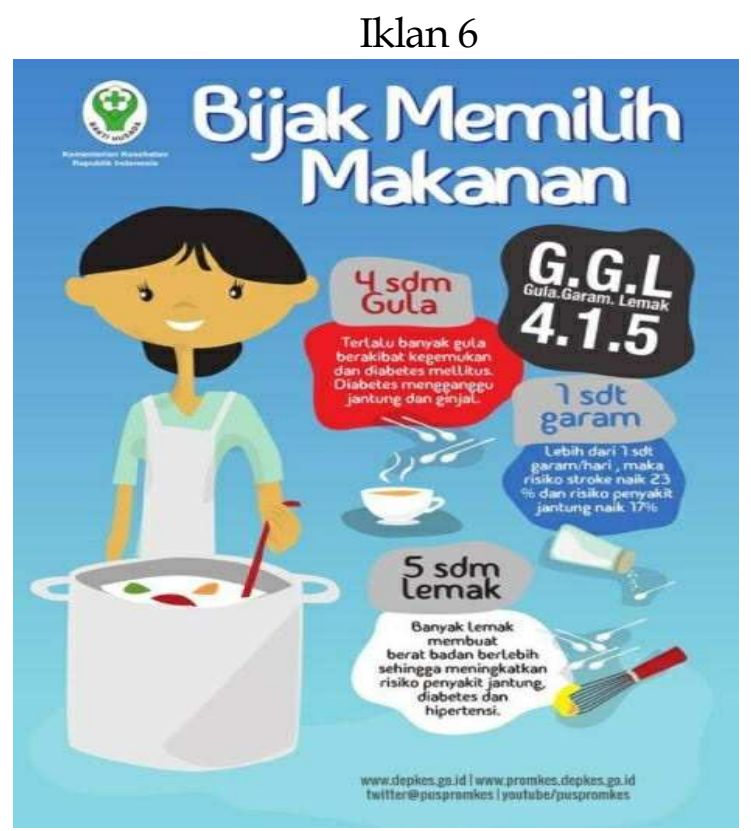

(sumber:

https:// srihardono.bantulkab.go.id/first/arti kel/279-YUK--BIJAK-MEMILIH-

MAKANAN-UNTUK-TUBUH-YANGSEHAT)

Iklan 6 tersebut mengandung tema "Memilih makanan", penjelasan GGL (gula, garam, lemak), ajakan secara implisit agar bijak memilih makanan, pembuat produk ialah Departemen Kesehatan, dan pelengkap berupa tulisan dikemas dalam blok berwarna dan ilustasi gambar orang yang sedang memasak.

(2) Iklan Layanan Masyarakat yangTak Lengkap

Iklan layanan masyarakat yang berunsur tidak lengkap, misalnya sebagaiberikut.

\section{Iklan 7}

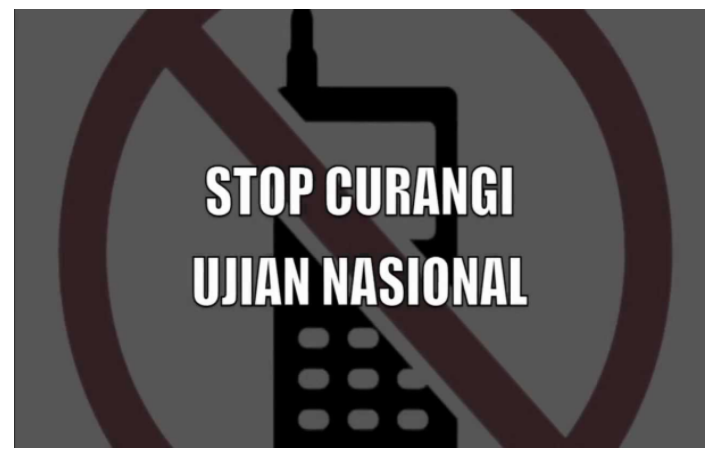

(sumber:

http:/ / ujianas20132014.blogspot.com/2013/ 11/stop-curangi-un.html)

Iklan 7 mengandung tema "Ujian nasional" dan perintah "Stop ujian nasional". Meskipun unsurnya tidak lengkap, iklan tersebut komu-nikatif dan mudah dipahami masyarakat, serta pesannya tersampaikan.

\subsection{Pemanfaatan Bahasa pada Teks}

(1) Pemanfaatan bahasa asing

Iklan layanan masyarakat dalam bentuk poster dalam kajian ini ialah berbahasa Indonesia. Namun, ada sejumlah iklan yang memanfaatkan bahasa asing (bahasa Inggris) sebagai "daya tarik" atau sebagai penguat pesan yang ingin disampaikan, seperti pada iklan berikut.

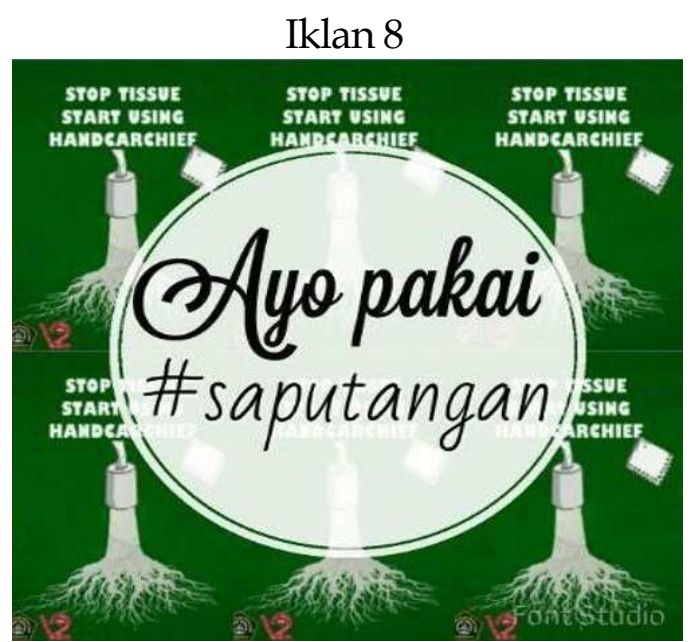

(sumber: https:/ / soundcloud.com/iffahsabrina-688409358/psa-lingkungan-hidup) 
Dalam iklan yang mengandung pesan utama ialah"ayopakai sapu tangan" tersebut terdapat unsur bahasa InggrisSTOP TISSUE, START USING HANDCACHIEF 'setop penggunaan tisu, mulailah menggunakan saputangan'. Unsur bahasa Inggris tersebut digunakan untuk memperkuat pesan tambahan yang diharapkan dapat memperkuat pesan utama,"ayo pakai sapu tangan".

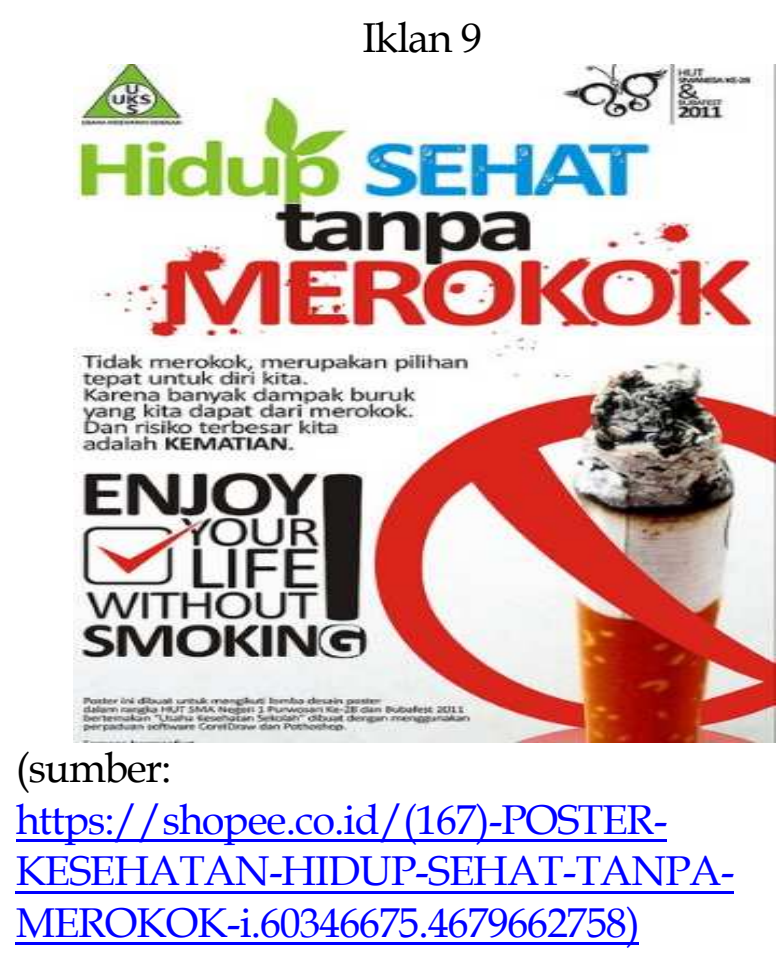

Dalam iklan tersebut digunakan bahasa Inggris ENJOY YOUR LIFE WITHOUT SMOKING 'nikmatilah hidup tanpa merokok'. Unsur bahasa Inggris tersebut dimanfaatkan sebagai daya tarik dan penguat pesan agar lebih diperhatikan dan dipedulikan. Sama halnya dengan iklan berikut (iklan 10), unsur Inggris Think before throwing' Berpikirlah sebelum membuang' juga merupakan penguat pesan perintah pada iklan utama Hidup sehat tanpa rokok.

\section{(2) Pemanfaatan gaya bahasa}

Iklan ialah sarana untuk menarik orang melakukan apa yang dianjurkan/ diperintahkan oleh pemproduksi iklan kepada khalayak.
Agar menarik, iklan memanfaatkan permainan bahasa, salah satunya gaya bahasa. Gaya bahasa yang dimanfaatkan, antaralain gaya bahasa asonansi-aliterasi (persamaam bunyi: klarifikasi, konfirmasi, validasi), yaitu untuk mempertegas iklan STOP HOAX, seperti berikut.

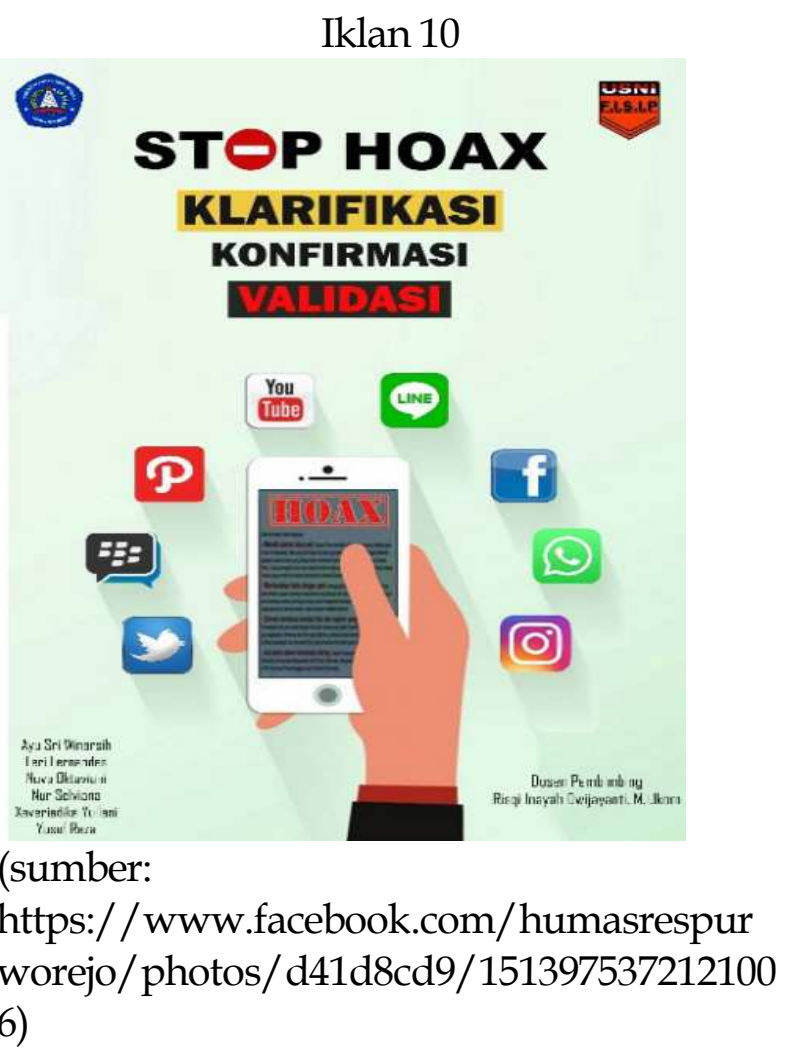

Contoh yang lain ialah iklan layanan masyarakat tentang pelestarian hutan. Pada iklan itu terdapat gaya bahasa analogi, yaitu hutan dianalogikan dengan dongeng, yaitu "hanya tinggal cerita". Gaya bahasa pararelisme, matikan rokok, sebelum rokok mematikanmu juga terdapat pada iklan setop merokok.

\subsection{Kekhasan Kosakata dalam Teks Iklan Layanan Masyarakat}

Iklan ialah berita atau pesan yang membujuk atau mendorong orang agar tertarik pada barang dan atau jasa yang ditawarkan.

Iklan layanan masyarakata ialah pesan yang membujuk atau mendorong orang agar mau 
melakukan apa yang ditawarkan. Agar mau melakukan apa yang ditawarkan, salah satunya diperlukan bahasa yang menarik. Bahasa yang digunakan dapat dikemas dengan kejelasan dan estetika bahasa yang membuat orang sadar akan pentingnya tawaran pada iklan layanan masyarakat itu. Berdasarkan data yang diperoleh, penawar-an dapat berbentuk imperatif dan berbentuk deklaratif meskipun keduanya merupakan "perintah" (ajakan atau larangan) untuk berbuat sesuatu.

Dalam bagian ini dideskripsikan kekhasan kosakata yang digunakan dalam teks iklan layanan masyarakat. Ada empat kelompok kekhasan kosakata, yaitu kosa-kata yang bernuansa perintah, larangan, pemberitahuan, dan ajakan.

\subsubsection{Kata Larangan}

Diksi yang bernuansa larangan yang sering digunakan dalam teks iklan ialah kata setop, jangan. Penggunaan kata SETOP, JANGAN terdapat pada contoh iklan berikut.

Iklan 11

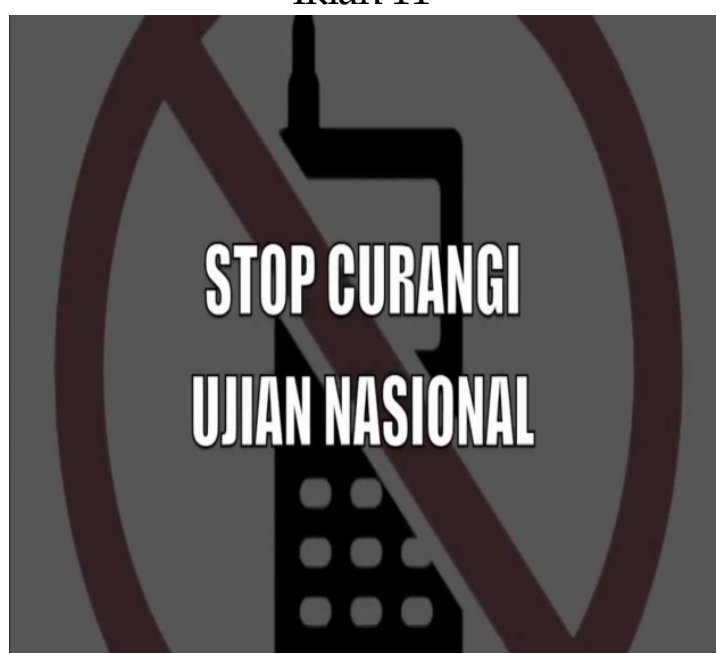

(sumber:

https://brainly.co.id/tugas/32244442)
Iklan 12

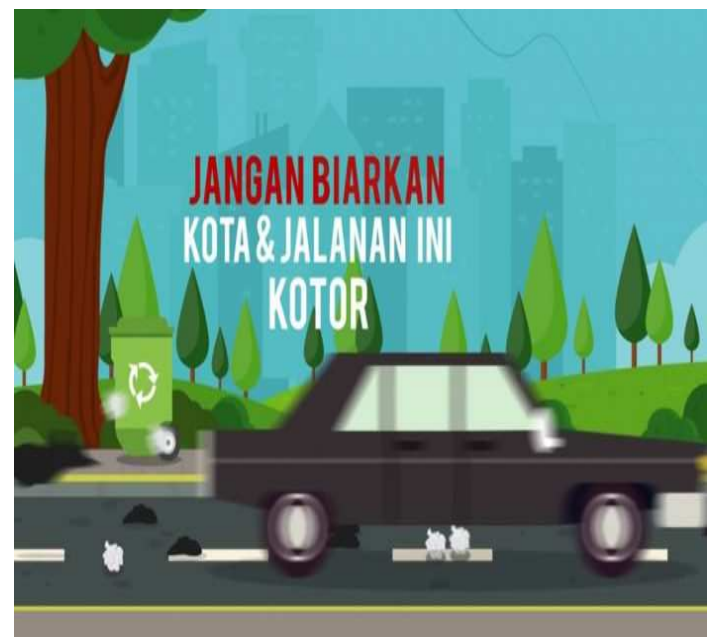

(sumber:

https://contohposter.com/terbaru/contoh-

gambar-iklan-kebersihan/iklan-layanan-

masyarakat-jangan-buang-sampah-

sembarangan)

\subsubsection{KataPerintah dan Imbauan}

Iklan layanan masyarakat yang bernuansa perintah atau imbauan menggunakan verba bersufiks $\{-k a n\}$ atau berklitika $\{-l a h\}$. Verba bersufiks\{-kan\} sebagai verba perintah atau imperatif yang bermakna "permintaan yang segera dilakukan", sedangkan verba berklitika \{-lah\} sebagai verba perintah pemersilakan atau imperatif yang bermakna "pemersilakan untuk bertindak seperti pada verbanya". Contohnya ialah pada teks iklan berikut.

\section{Iklan 13}

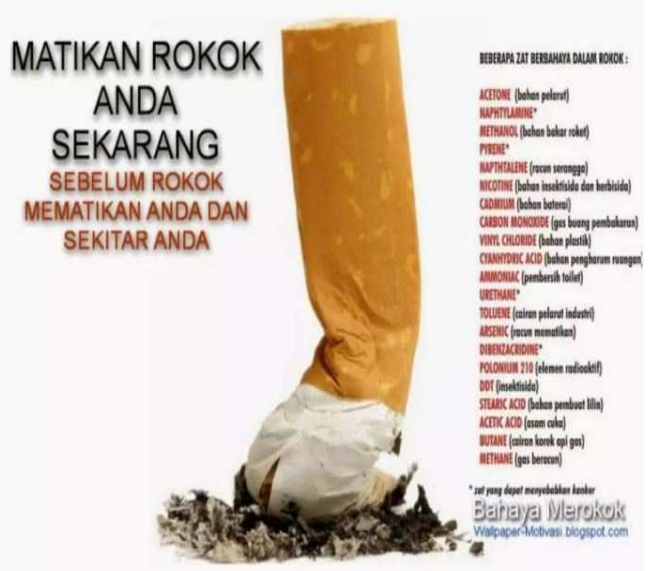


(sumber:

https://i1.wp.com/liputanhukum.com/wpcontent/uploads/2016/10/ROKOKMEMBUNUHMU-IKLAN-300-X-250OL.jpg?ssl=1)

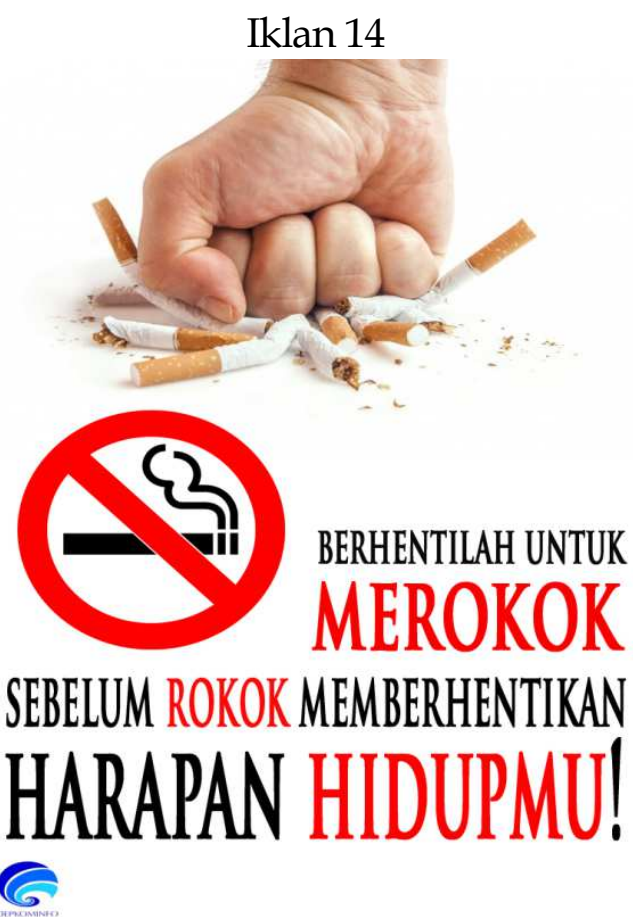

(sumber: https://lenteramata.com/contohiklan-layanan-masyarakat/)

Iklan 13 menggunakan kata MATIKAN (rokok Anda) dan iklan 13 menggunakan kata BERHENTILAH (merokok). Kedua diksi itu mencerminkan perintah.

\subsubsection{Kata Ajakan}

Iklan layanan masyarakat merupakan ajakan untuk berperilaku dan/atau bertindak melakukan sesuatu. Salah satu cara dengan direktif ajakan. Diksi yang bermakna ajakan dalam (ILM) ialah kata AYO, MARI, seperti pada contoth iklan berikut.
Iklan 15

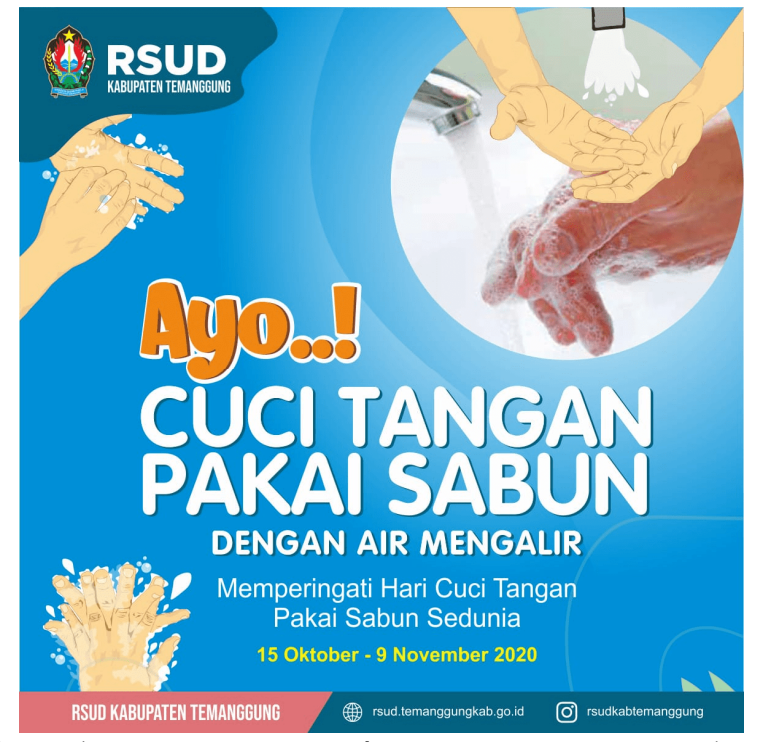

(sumber:

/ayo-cuci-tangan-pakaisarsud.temanggungkab.go.id/home/berita/ 302bun)

Iklan 16

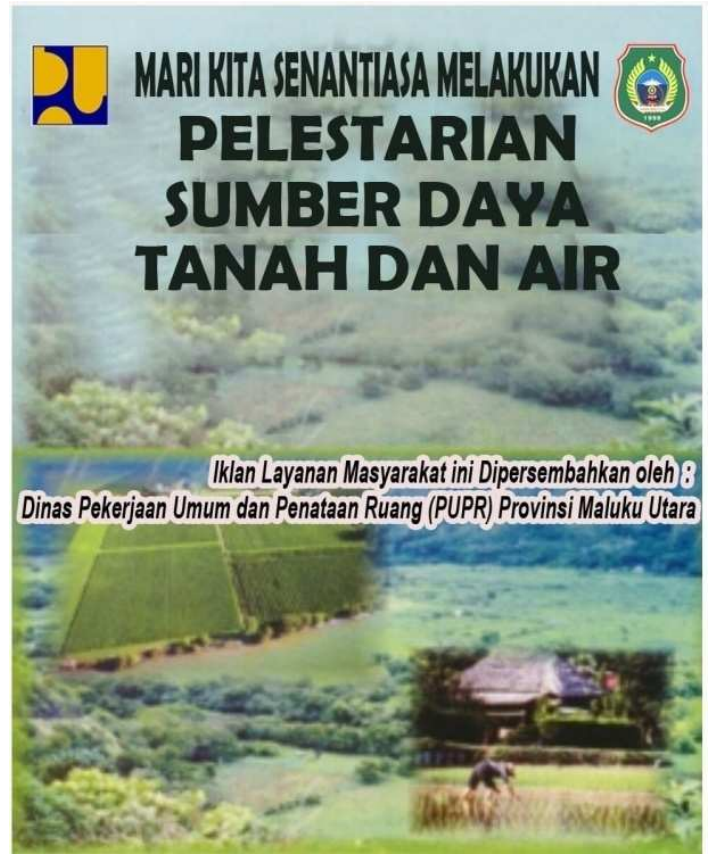

(sumber:

https:/ / malutnews.com/category/ promone ws/page/6/)

Teks iklan 14 tertulis AYO, cuci tanganmu pakai sabun!! Kuman mati, tangan hepi. Teks iklan 15 tertulis MARI kita senantiasa melakukan pelestarian sumber daya tanah 
dan air. Kedua teks ILMtersebut mengajak untuk berbuat sesuatu dengan diksi ajakan ayo dan mari.

\subsubsection{Kata Pemberitahuan}

Iklan layanan masyarakat bertujuan mengajak masyarakat. Salah satu mengajak adalah dengan memanfaatkan bahasa. Bahasa yang dimanfaatkan itu bemakna direktif atau perintah. Meskipun perintah, ada direktif langsung dan direktif taklangsung; ada yang dengan menggunakan kata perintah persilakan (silakan), diksi perintak (afiks -kan, klitika -lah); diksi ajakan, menggunakan kata ayo, mari; dan diksi yang hanya pemberitahuan/deklaratif. Berikut ialah direktif pemberitahuan pada iklan layanan masyarakat.

\section{Iklan 17}

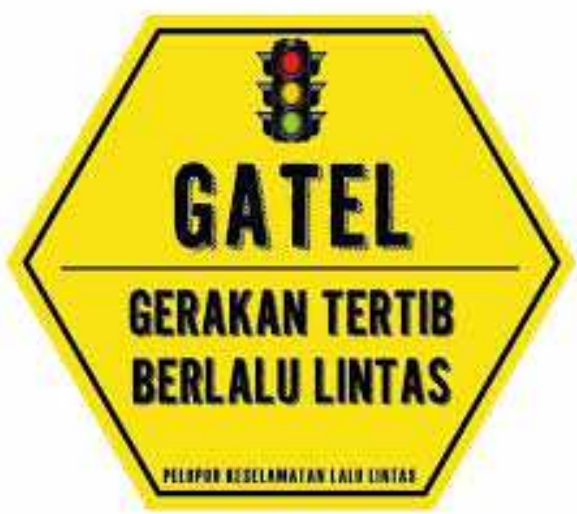

(sumber: $\quad \underline{\text { https://m.facebook.com/Iklan- }}$ Layanan-Masyarakat-Tertib-Lalu-lintas$2203355193224768 /$ ? th_ $=\% 2 \mathrm{Cg}$ )

Iklan tersebut digunakan untuk mengimbau agar masyarakat tertib berlalu lintas, tetapi cara mengimbaunya dengan akronim GATEL (gerakan tertib berlalu lintas).
Iklan 18

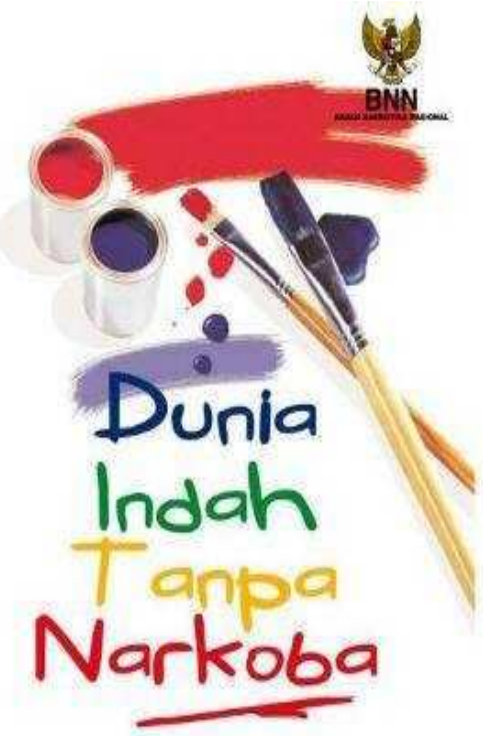

(sumber:

https://kejarcita.id/bank/questions/132398)

Iklan 18 bertujuan mengajak untuk menghindari narkoba, cara beriklannya dengan hanya memberitahukan bahwa DUNIA INDAH TANPA NARKOBA. Demikian juga pada iklan 19 berikut.

Iklan 19

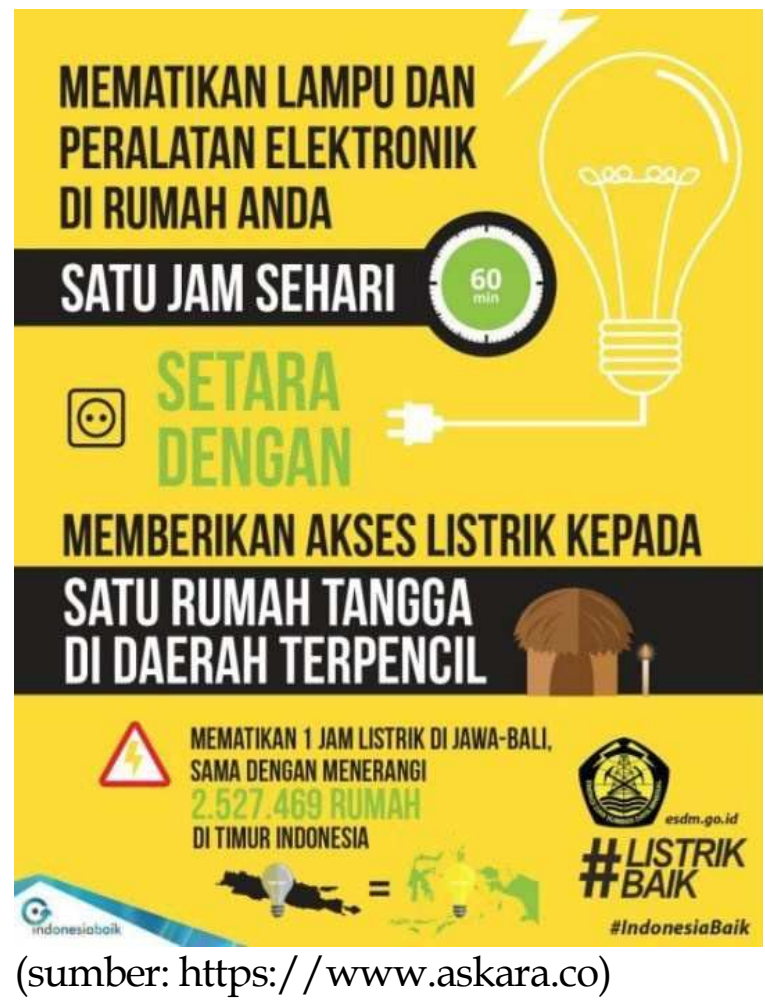


Iklan 19 tersebut mengajak mayarakat untuk menghemat energi listrik. Cara beriklannya dengan memberikan teks deklaratif yang cukup panjang, yaitu MEMATIKAN LAMPU DAN PERALATAN ELEKTRONIKDI RUMAH ANDA SATU JAM SEHARI, SETARA DENGAN MEMBERIKAN AKSES LISTRIK KEPADA SATU DAERAH TERPENCIL. MEMATIKAN 1JAM LISTRIK DI JAWA-BALI SAMA DENGAN MENERANGI 2.527.469 RUMAH DI TIMUR INDONESIA. Teks tersebut merupakan teks pemberitahuan terkait manfaat mematikan listrik 1 jam sehari.

\subsection{Kekhasan Pesan pada Teks Iklan Layanan Masyarakat}

Pada dasarnya setiap jenis teks memiliki kekhasan, demikian juga teks iklan, kususnya teks iklan layanan masyarakat. Kekhasan itu ialah bahwa maksud penyampaian pesan ialah untuk memerintah, baik memerintah secara langsung ataupun secara taklangsung. Langsung dan tidak langsung penyampaian pesan tersebut ditandai dengan bentuk bahasanya. Penyampaian bahasa teks iklan secara langsung dalam penelitian ini disebut bentuk imperatif langsung; penyampian bahasa teks iklan secara tidak langsung disebut bentuk imperatif taklangsung.

\subsubsection{Bentuk Imperatif Langsung pada Teks} Iklan

Pada bagian ini dibahas bentuk imperatif langsung terkait dengan fokus imperatif dan bentuk gramatika pendukung imperatif langsung. Untuk itu, pembahasan terbagi atas empat subbagian, yaitu (1) fokus imperatif pada klausa, (2) fokus imperatif pada kalimat, (3) bentuk gramatika pendukung imperatif, dan (4) bentuk leksikal pendukung imperatif.

\section{(1) Fokus imperatif pada klausa}

Pesan imperatif pada teks iklan layanan masyarakat sudah dapat termaknai hanya pada klausa. Artinya, hanya berhenti pada sebuah klausa pada teks itu, pesan perintah langsung dapat dipahami, misalnya contoh ketiga klausa berikut pada teks iklan yang berbeda: setop hoaks, setop aborsi, dan ayo sekolah.

Klausa setop hoaks langsung cepat dimaknai bahwa kita diperintahkan untuk menyetop tindakan membuat hoaks (berita bohong), demikian juga setop aborsi langsung cepat dimaknai kita diperintahkan untuk tidak melakukan tindak aborsi (pengguguran janin dalam kandungan). Klausaayo sekolah pada teks iklan layanan masyarakat dengan langsung dapat dimaknai perintah untuk bersekolah.

\section{(2) Fokus imperatif pada kalimat}

Pesan imperatif pada teks iklan layanan masyarakat dapat langsung dimaknai dalam bentuk kalimat. Artinya, muncul makna imperafif (perintah) ada pada sebuah kalimat dalam teks itu. Misalnya Jangan biarkan kota dan jalanan ini kotor. Ada dua segmen pada kalimat tersebut, yaitu Jangan biarkan kota dan jalanan ini kotor. Yang sebagai faktor utama makna "perintah" ialah segmen jangan biarkan dan segmen kotor. Kedua segmen itu harus hadir sebagai makna imperatif, dan keduanya mendukung dalam satu kalimat.

\section{(3) Bentuk gramatikal pendukung} imperatif

Makna imperatif pada iklan layanan masyarakat didukung oleh bentuk verba bersufiks (ber-akhiran), yaitu (a) bentuk verba D-kan, (b) bentuk verba D-i, (c) bentuk verba $D$, dan verba berklitika -lah. Bnetuk-bentuk verba seperti itu merupakan verba bernuansa imperatif.

(4) Bentuk leksikal imperatif

Bentuk leksikal yang digunakan untuk imperatif (memerintah) dalam ILM digunakan diksi berikut: (a) Setop, (b) Jangan, (c) Ayo, dan (d) Mari. 


\section{Bentuk Imperatif Taklangsung}

Imperatif taklangsung dalam teks ILM ialah perintah yang dimaksud tidak dituturkan secara langsung (secara hariah), tetapi diwujudkan dalam kalimatdeklaratif. Namun, teks itu menyiratkan perintah (imperatif). Dalam teks ILM ini terdapat kalimat atau bentuk bahasa imperatif taklangsung, seperti berikut.

(a) Hidup sehat tanpa merokok.

(b) Hidup sehat tanpa narkoba.

(c) Dunia indah tanpa narkoba.

(d) Narkoba musuh kita, bukan teman kita.

(e) Kehamilan 100 hari pertama periode emas janin.

(f) Aku generasi peduli pajak.

(g) Gejala dan pencegahan diabetes: Pola makan.

(h) Merokok= menggali kuburan sendiri.

(i) Ikan bergizi tinggi, sehat, dan enak.

(j) Bahaya menggunakan gadget saat berkendara.

(k) Mematikan lampu dan peralatan elektronik satu jam sehari setara dengan memberikan akses listrik kepada satu rumah tangga di daerah terpencil.

\section{Simpulan}

Ada lima simpulan yang dapat diambil dari pembahasan penelitian ini berkaitan dengan ada lima masalah penelitian, sebagai berikut.

1. Ada tiga iklan layanan masyarakat, yaitu perpaduan bahasa dan gambar, hanya gambar, dan hanya teks bahasa tulis. Ketiga bentuk tersebut merupakan teks iklan, meskipun hanya gambar (pada prinsipnya gambar dapat ditafsirkan sebagai komunikasi nonverbal).

2. Komposisi teks iklan layanan masyarakat memiliki unsur teks sebagai tema iklan, teks sebagai penjelas tema, dan teks pemproduksi iklan. Adaiklan yang memiliki komposisi lengkap ada yang tidak lengkap. Meskipun tidak lengkap, tema iklan wajib hadir sebagai teks iklan.
3. Pemanfaatan teks dalam iklan layanan masyarakat ialah untuk tujuan melarang, memerintah, mengajak, dan mengimbau.

4. Kekhasan kosakata iklan layanan masyarakat ialah adanya penggunaan kata yang menyuratkan perintah dan yang menyiratkan perintah sehingga teksnya sebagai perintah langsung dan taklangsung.

5. Bentuk imperatif langsung pada iklan layanan masyarakat ditunjukkan dengan afiksasi -kan, -i, dan klitika -lah yang melekat pada verba perintah. Bentuk imperatif taklangsung pada iklan layanan masyarakat ditunjukkan dengan kalimat deklaratif.

\section{Daftar Pustaka}

Erikha, Fajar. 2018. “Konsep Lanskap Linguistik pada Papan Nama Jalan Kerajaan (Râjamârga): Studi Kasus di Kota Yogyakarta." Paradigma, Jurnal Kajian Budaya 8(1):38. https:/ / doi.org/10.17510/paradigma. v8i1.231

Pribady, Haries. 2018. "Pengantar Metodologi Penelitian Linguistik." (June). https:/ / doi.org/10.31219/osf.io/8ywk 3

Program, Mahasiswa, Studi Magister, Ilmu Komunikasi, Fisip Undip, danAngkatan VI. 2015. "Strategi Kreatif Iklan Layanan Masyarakat (Ilm) dalam Pemasaran Sosial." INTERAKSI: Jurnal Ilmu Komunikasi 4(2):158-64.

Purnami, Wening Handri. 2017. “Discourse Study oF Food Servive Advertisment." Widyaparwa 45(2):137-50. https:/ / doi.org/10.26499/wdprw.v45i 2.232 
Rahmanadia, Hyunisa. 2012. "DALAM BAHASA IKLAN ANAK An Analysis of Schemata Usage in Children Discourse Advertisement." (August):10 20. https://doi.org/10.26499/rnh.v1i1.4

Setiawan, Agus. 2015. “Strategi Kreatif Iklan Layanan Masyarakat (Tinjauan Perancangan ILM Karya Mahasiswa DKV UDINUS)." ANDHARUPA: Jurnal Desain Komunikasi Visual \& Multimedia 1(01):17-32.

https://doi.org/10.33633/andharupa.v $1 \mathrm{i} 01.954$

Setiyanto, Edi. 2013. "Metapesan di Balik Parodi Iklan Djarum 76." Widyaparwa 41(2).

Shofa, Fathin, and Meina Astri Utami. 2017. "Menyingkap Makna dan Tanda dalam Iklan Rokok A-Mild Versi 'Hasrat': Kajian Semiotika." Ranah: Jurnal Kajian Bahasa 6(2):180. https:/ / doi.org/10.26499/rnh.v6i2.266

Sukamto, Katharina Endriati, dan Dorien
Kartikawangi. 2012. "Sebuah Kajian Komunikasi Dan Bahasa Terhadap Iklan TV Produk ' CITRA .'" 1:1-13. https://doi.org/10.26499/rnh.v1i2.3

Sumarsih, Nanik. 2018. “Strategi dan Fungsi Tindak Tutur Direktif dalam Poster Pendidikan." Widyaparwa 46(1):49-60. https:/ / doi.org/10.26499/wdprw.v46i 1.163

Suryo Nugroho, Agung. 2012. "Analisis Wacana Kritis terhadap Iklan-Iklan Pajak dalam Pembentukan Realitas pada Kehidupan Masyarakat." Ranah: Jurnal Kajian Bahasa 1(1):56. https:/ / doi.org/10.26499/rnh.v1i1.18

Suwitra, I. Made, dan Nyoman Suarjana. 2018. "Iklan Layanan Kesehatan Masyarakat (Ilkm); Kajian Semiotik." Jurnal Kesehatan Terpadu2(2):82-90. https:// doi.org/10.36002/jkt.v2i2.539

Wati. 2015. “'Olah Kata dalam Media Luar Ruang Sebagai Industri Kreatif.'” Ranah 4(2):164-78. 